\title{
A Educação Ambiental nos trabalhos do Encontro Nacional de Ensino de Química
}

\author{
Environmental Education in the work of the National Chemistry Teaching Meeting \\ La Educación Ambiental en el trabajo del Encuentro Nacional Docente de Química
}

Recebido: 19/12/2021 | Revisado: 24/12/2021 | Aceito: 30/12/2021 | Publicado: 31/12/2021

\author{
Alessandra Ester de Souza \\ ORCID: https://orcid.org/0000-0002-4347-2062 \\ Universidade Federal Paranaense, Brasil \\ E-mail: ale.souza89@gmail.com \\ George Hideki Sakae \\ ORCID: https://orcid.org/0000-0002-9881-3143 \\ Universidade Federal da Integração Latino-Americana, Brasil \\ E-mail: georgesakae@gmail.com \\ Maria das Graças Cleophas \\ ORCID: https://orcid.org/0000-0002-5611-2437 \\ Universidade Federal da Integração Latino-Americana, Brasil \\ E-mail:mgcp76@gmail.com
}

\begin{abstract}
Resumo
O presente artigo buscou investigar e traçar um perfil de como a Educação Ambiental (EA) vem sendo abordada no ensino de química. Para tanto, foram analisados 64 trabalhos completos obtidos a partir da busca nos diretórios gratuitos que compõem os anais do Encontro Nacional de Ensino de Química (ENEQ) publicados em 5 (cinco) edições do evento no período de 2010 a 2018. A metodologia teve uma abordagem qualitativa e utilizou a análise documental com foco na Revisão Sistemática de Literatura (RSL). Para apreciação dos dados levantados foi aplicada a técnica de Análise de Conteúdo de Bardin. Como resultado, foi constatado um crescimento na produção de trabalhos relacionados à EA ao longo dos anos que podem ter sido impulsionados pela exponencialidade nas formas e meios de divulgação e demonstram um panorama sobre a existência de diversas abordagens, metodologias e referenciais abordados nos diferentes níveis e segmentos da educação básica, Ensino Superior e comunidades. Como conclusão, percebe-se que a EA quando atrelada ao ensino de química ainda necessita de pesquisas e divulgação de práticas de ensino que abordem a Educação Ambiental em suas múltiplas dimensões.
\end{abstract}

Palavras-chave: Educação ambiental; Revisão sistemática da literatura; Ensino de química.

\begin{abstract}
This article sought to investigate and draw a profile of how Environmental Education (EE) has been addressed in the teaching of chemistry. For this, 64 full papers obtained from the search in free directories that make up the annals of the National Meeting on Teaching of Chemistry(ENEQ) published in 5 (five) editions of the event from 2010 to 2018 were analyzed. The methodology had a qualitative approach and used document analysis with a focus on Systematic Literature Review (RSL). Bardin's Content Analysis technique was applied to assess the data collected, As a result, a growth in the production of works related to EA over the years that may have been driven by exponentially in the forms and means of dissemination and demonstrate an overview of the existence of various approaches, methodologies and references addressed at different levels and segments of basic education, higher education and communities. In conclusion, we realize that EA, when linked to the teaching of chemistry, still needs research and dissemination of teaching practices that address Environmental Education in its multiple dimensions.
\end{abstract}

Keywords: Environmental education; Systematic literature review; Chemistry teaching.

\section{Resumen}

Este artículo buscó investigar y trazar un perfil de cómo se ha abordado la Educación Ambiental (EA) en la enseñanza de la química. Para ello, se analizaron 64 trabajos completos obtenidos de la búsqueda en los directorios gratuitos que componen los anales del Encuentro Nacional de Docencia en Química (ENEQ) publicados en 5 (cinco) ediciones del evento en el período 2010 a 2018. Enfoque cualitativo y análisis de documentos usados con un enfoque en la revisión sistemática de la literatura (RSL). Para evaluar los datos recopilados se aplicó la técnica de Análisis de contenido de Bardin. Como resultado, se encontró un crecimiento en la producción de trabajos relacionados con la EA a lo largo de los años, que puede haber sido impulsado por la exponencialidad en las formas y medios de difusión y demostrar un panorama de la existencia de diferentes enfoques, metodologías y referencias abordadas. en diferentes niveles y segmentos de la educación básica, educación superior y comunidades. En conclusión, es claro que la EA, ligada a la enseñanza de la química, aún necesita la investigación y difusión de prácticas docentes que aborden la Educación Ambiental en sus múltiples dimensiones.

Palabras clave: Educación ambiental; Revisión sistemática de la literatura; Enseñanza de la química. 


\section{Introdução}

Segundo Emery, Santos e Bianchi (2010) a química é natureza, vida, morte, mudança e faz parte de uma profunda relação entre diversos campos antagônicos e inseparáveis, e participante também da relação que o ser humano estabelece com o seu meio. Pode-se, nesse contexto, desenvolver-se a Educação Ambiental (EA) como instrumento de trabalho associado a inúmeras aplicações. Este trabalho parte da premissa de que o estudo da química é um campo que permite conhecimento e diálogo apropriado para a Educação Ambiental como foco no estabelecimento de um vínculo entre o ser vivo e a natureza e, portanto, destes dois com o mundo. Desse modo, a relação entre a vida humana e o meio ambiente pode ser explicada logicamente por meio de habilidades e conhecimentos científicos/químicos (Tanaka, 2000).

Para alcançar o propósito deste trabalho, realizou-se um estudo de caráter investigativo utilizando-se da premissa em realizar um panorama de como a Educação Ambiental está difundida no ensino de química, seja por um caráter teórico ou aplicacional. Como metodologia, utilizou-se a pesquisa documental ao analisar trabalhos publicados nos no período de 2010 a 2018 das edições do Encontro Nacional de Ensino de Química (ENEQ). Este evento consiste em um encontro bianual criado pela Divisão de Ensino da Sociedade Brasileira de Química (SBQ). Cabe destacar que o ENEQ, no decorrer dos anos, tem reunido docentes dos diferentes níveis de ensino, estudantes de graduação, pós-graduação e até do ensino médio, com o intuito de discutir temas que norteiam a educação química. Portanto, o evento tem estimulado e possibilitado a divulgação de pesquisas e discussões, experiências entre as diversas subáreas do ensino de química, incluindo a EA.

Pretende-se oportunizar a utilização do estudo realizado neste trabalho como ferramenta que busca compreender as nuances de como a Educação Ambiental é abordada, pesquisada e refletida no âmbito educacional da química. Nessa direção, o objetivo deste trabalho é, por meio da análise da articulação do ensino de Química com a Educação Ambiental, identificar e discutir a pluralidade e diversidade de propostas teórico-metodológicas divulgadas nos Anais do ENEQ para traçar um perfil, visando identificar as diversas concepções ambientais existentes, na intenção de proporcionar considerações e observações que contribuam para o debate sobre a EA.

\subsection{Educação Ambiental e o Ensino de Química}

Alguns pesquisadores (Kato, 2011; Silva, 2010; Santos, 2018) defendem que o ensino de Química deve seguir um novo caminho, não apenas se limitando aos conceitos químicos, mas, sobretudo, que consiga procurar entender a sociedade ao colocar em prática um olhar reflexivo diante das distintas situações - de caráter generalista, aprofundado ou até mesmo problemáticas mundiais - que cercam o nosso cotidiano. Desta forma, os objetivos atrelados ao ensino de química vêm sendo revistos e, com isto, verifica-se que as críticas ao ensino tradicional residem na passividade imposta à conduta dos estudantes diante da sua própria construção da aprendizagem, ainda que tal ator não esteja plenamente consciente disso. Por outro lado, busca-se, a cada dia, o desenvolvimento de uma educação voltada para a cidadania e para a capacidade de tomada de decisões ao tentar articular o conhecimento químico de forma problematizada com o contexto social, com a abertura democrática, permitindo assim, que os educandos tenham condições e espaços para desenvolver pensamentos críticos e, gradualmente, participar cada vez mais efetivamente das decisões relacionadas ao desenvolvimento científico, tecnológico e social que causam impactos de modo direto e indireto ao meio ambiente.

Em acréscimo, Bowers e Creamer (2021) defendem que a educação ambiental (EA) é uma ferramenta que pode criar uma cidadania mais informada sobre o meio ambiente. Dessa forma, para alcançar uma educação que tenha como alicerce uma formação cidadã é imprescindível a conscientização sobre o meio ambiente em que vivemos. Deste modo, ao utilizar esta vertente é necessário articular os temas pertencentes ao currículo de química com os problemas ambientais, buscando fomentar a construção de um "saber ambiental" (Leff, 2007), que consiga formar cidadãos críticos e, consequentemente, conscientes. Segundo Layrargues (2004) a Educação Ambiental é o nome que historicamente se convencionou dar às práticas educativas 
relacionadas à questão ambiental. Desde o início do uso do termo "Educação Ambiental", foram tecidas diversas classificações e denominações que se associaram às concepções que deram sentido às práticas e reflexões pedagógicas relacionadas à questão ambiental.

De modo geral, podemos observar, conforme se desenha na pesquisa aqui descrita, um considerável aumento na produção de projetos, pesquisas e propostas práticas e teóricas produzidas por diferentes segmentos da sociedade. Tais políticas e ações políticas buscam contribuir para a consolidação de um campo de estudo da Educação Ambiental para gerar possibilidades de melhoria na qualidade de vida - individual e coletiva - a partir de ações educativas exitosas que propiciem mudanças positivas nas relações entre o homem e o meio.

\section{Metodologia}

A metodologia desta pesquisa é uma abordagem qualitativa. Este tipo de abordagem se mostra cada vez mais recorrente porque "os dados produzidos e coletados apresentam cada vez mais uma interpretação crítica e argumentativa dos fenômenos estudados ao trazer uma reflexão sobre o objeto de estudo" (Tozoni-Reis, 2009, p. 33). Como complemento metodológico, utilizou-se a técnica de análise documental com foco em uma Revisão Sistemática de Literatura (RSL). Para tanto, o ponto de partida considera os pressupostos metodológicos sobre RSL propostos por Cleophas e Francisco (2018) e Donato (2019), adotando 5 (cinco) etapas para o desenvolvimento da pesquisa. A Figura 1 apresenta a estruturação sistemática da RSL aplicada.

Figura 1 - Representação Sistemática da RSL aplicada à pesquisa qualitativa.

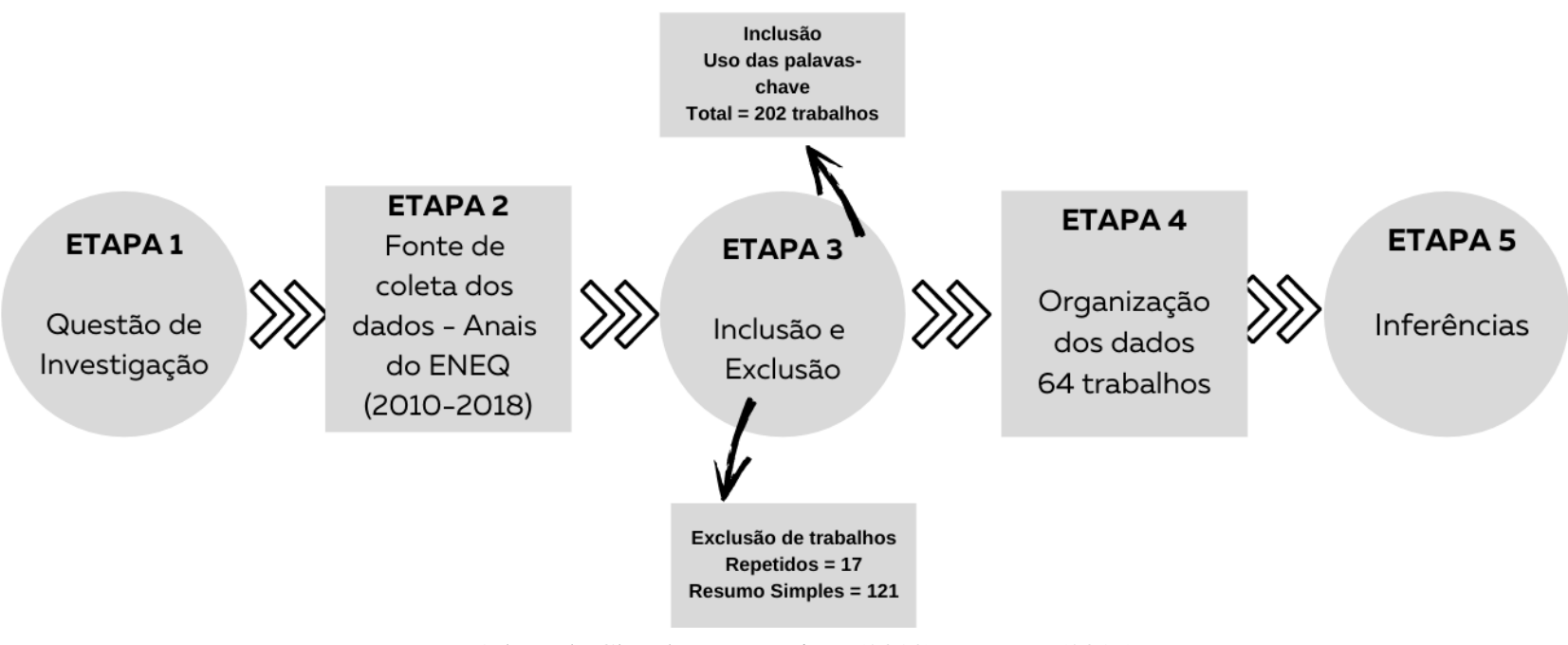

Fonte: Adaptada Cleophas e Francisco (2018) e Donato (2019).

Percebe-se, por meio da Figura 1, que a RSL adotado é composta por etapas que foram essenciais para atender os objetivos da pesquisa, sendo elas:

ETAPA 1: Questão de investigação: inicialmente partiu-se de um problema cuja finalidade foi atender o objetivo da pesquisa, ou seja, traçar um perfil sobre como a EA está sendo abordada no ensino de química. Deste modo, questionou-se “Como a Educação Ambiental (EA) está sendo difundida no Ensino de Química?".

ETAPA 2: Estratégia de pesquisa na literatura: os trabalhos analisados foram obtidos a partir da busca nos diretórios gratuitos que compõem os anais dos ENEQs produzidos nas 5 (cinco) edições mais recentes (2010-2018).

ETAPA 3: Os critérios de inclusão e de exclusão: o levantamento bibliográfico considerou o seguinte espectro de 
palavras-chave: Educação Ambiental; Ambiental; Sustentabilidade; Ambiente; Conscientização. Com a busca localizou-se um total de 164 artigos (trabalhos completos), dos quais foram selecionados 64, optando-se apenas pela seleção de trabalhos completos. Este critério foi aplicado ao considerar que a quantidade de informação contida nesse tipo de formato de trabalho é maior e permite uma fundamentação e classificação mais apurada das análises. Além disso, é importante destacar que um mesmo artigo pode ser incluído em mais de uma categoria devido a sua especificidade em adequar-se em diferentes categorias de análise.

ETAPA 4: Organização dos dados levantados: nesta etapa ocorreu a organização dos dados coletados. Para isso, elaboraram-se categorias de análise, construção de gráficos, sistematização e discussão dos resultados da pesquisa.

ETAPA 5: Inferência: Nesta parte, os pesquisadores apresentam a compreensão dos resultados, delineiam tendências, implicações e carências para o problema que deu início a pesquisa, utilizando-se dos referenciais teóricos.

Por fim, utilizou-se como técnica para apreciação dos dados a Análise de Conteúdo de Bardin (1977). Tal técnica é definida pela autora como sendo "um conjunto de técnicas de análise de comunicações que visam obter, por meio de procedimentos sistemáticos e objetivos de descrição do conteúdo da mensagem, indicadores (quantitativos ou não) que permitem a inferência do conhecimento das condições de produção/recepção (variáveis inferidas) dessas mensagens" (Bardin,1977, p. 42). Assim, para a organização dos dados levantados, dos 64 trabalhos completos selecionados, optou-se em realizar um processo categorial que resultou na estruturação das categorias que dão aporte para responder à questão de investigação proposta, sendo elas:

1) Cronologia de incidência da Educação Ambiental no ENEQ;

2) Níveis educacionais envolvidos nas discussões e/ou atividades atreladas à EA;

3) Temáticas ambientais;

4) Características Metodológicas (Métodos de pesquisa; Procedimentos de coleta de dados e Práticas pedagógicas); e

5) Referenciais teóricos mais utilizados.

A partir dessas categorias, os trabalhos completos foram organizados e quantificados, formando um inventário de registro que embasou a inferência que deu subsídios para elaborar a discussão e a interpretação final dos resultados.

\section{Resultados e Discussão}

\subsection{Cronologia de incidência da educação ambiental no ENEQ}

Num contexto geral, todos os trabalhos foram inicialmente categorizados quanto à abordagem resumida ou completa, quando da submissão e apresentação no ENEQ. Analisando as 5 edições mais recentes do ENEQ (2010-2018) foi construído o Gráfico 1, que apresenta a distribuição destes trabalhos. 
Gráfico 1 - Cronologia da EA, nos formatos resumo e trabalho completo, nos ENEQs.

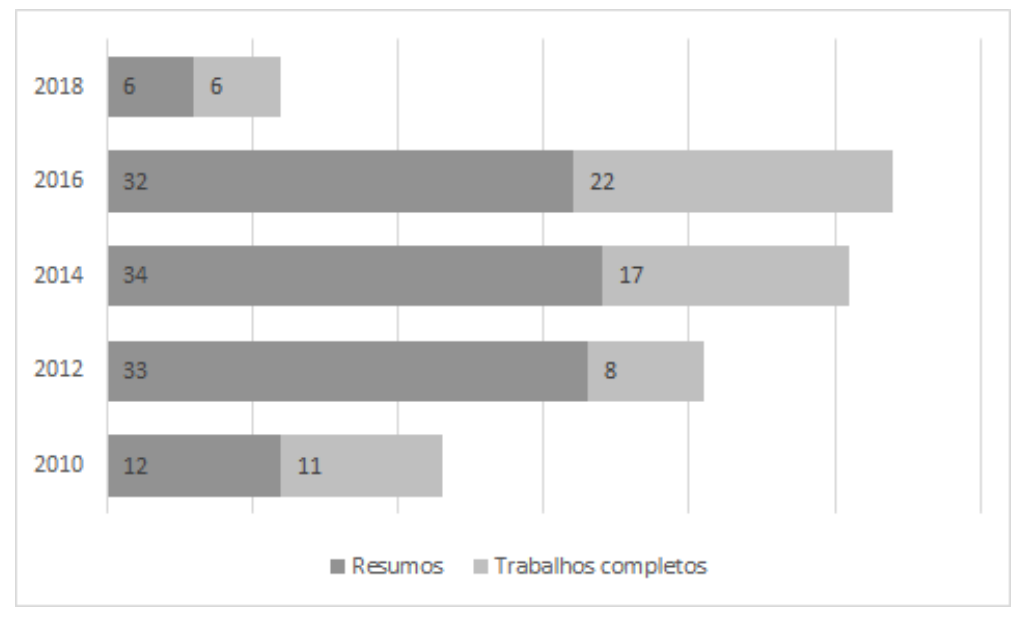

Fonte: Autores.

Foi possível observar uma tendência crescente das publicações de trabalhos (resumos simples e trabalhos completos) entre os anos de 2010 e 2016 relacionados à EA na área do ensino da química. Este crescimento de divulgações na EA também foi observado no trabalho de Marques et al. (2019), no qual é descrito a Frequência de publicação em EA no primeiro quinquênio do século XXI. No Brasil, a EA vem ganhando espaço nas pesquisas acadêmicas e científicas no ensino de ciências e consiste de uma área relativamente nova que despontou a partir da década de 90 (Megid-Neto, 1999). Segundo o INEP (2004), a preocupação com o meio ambiente permeia, cada vez mais, a área da educação. A EA é uma forma envolvente de educação que por execução de um processo pedagógico participativo busca uma consciência crítica sobre os problemas do ambiente.

Ainda, ao observar o Gráfico 1, percebe-se uma queda acentuada na divulgação de trabalhos totais, ou seja, isto representa a junção entre trabalhos completos e resumos simples em cerca de $78 \%$. Já a redução de publicação de trabalhos completos no ENEQ no ano de 2018 foi em torno de 73\%. Assim, foi possível constatar que em 2018 houve uma diminuição nas publicações relacionadas à EA no ENEQ, isto pode estar intimamente ligada ao baixo número de trabalhos inscritos no evento quando comparado às edições anteriores.

\subsection{Níveis educacionais envolvidos nas discussões e/ou atividades atreladas à EA}

O Gráfico 2 apresenta o quantitativo de trabalhos completos publicados nos ENEQs em relação aos diferentes níveis da educação. 
Gráfico 2 - Quantitativo de trabalhos completos publicados nos ENEQs em relação aos diferentes níveis da educação.

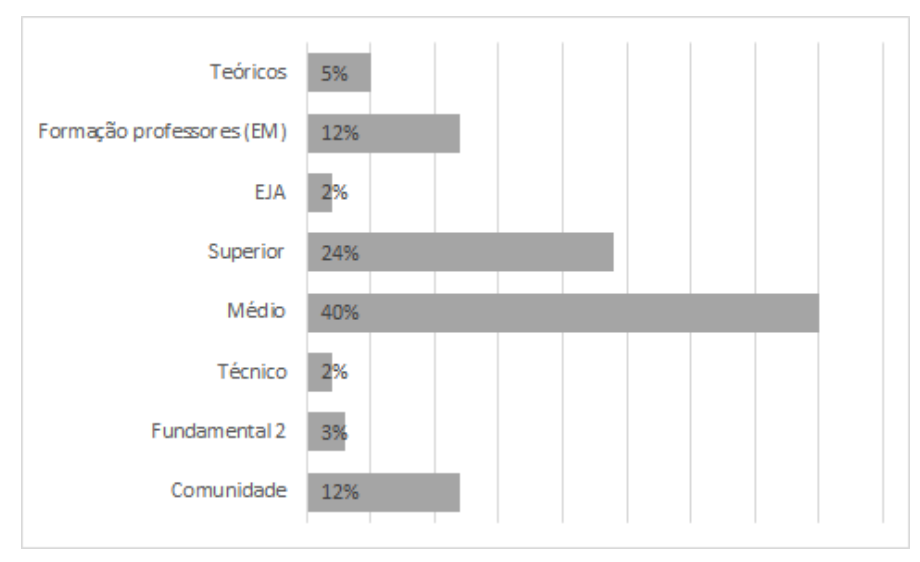

Fonte: Autores.

O índice de publicações que discutiam a EA no Ensino Fundamental II foi de 3\%, no ensino Técnico houve apenas $2 \%$ e com a Educação de Jovens e Adultos (EJA) foi encontrado apenas 2\% dos trabalhos apresentados nos eventos. Mesmo apresentando resultados pouco expressivos, observa-se que a EA vem sendo abordada no ensino química em todos os níveis da educação, isso vai ao encontro da Lei n. ${ }^{\circ} 9.795$, de 27 de abril de 1999, regulamentada pelo Decreto ${ }^{\circ} 4.281$, de 25 de junho de 2002, que dispõe

(...) especificamente sobre a Educação Ambiental (EA) e institui a Política Nacional de Educação Ambiental (PNEA), como componente essencial e permanente da educação nacional, devendo estar presente, de forma articulada, em todos os níveis e modalidades do processo educativo (BRASIL, 2012, p.1)

Percebeu-se que a maior concentração dos trabalhos estava voltada para ações desenvolvidas e aplicadas no Ensino Médio, com percentual de 40\%. Pode-se relacionar este alto percentual com o fato da disciplina de química estar num contexto isolado (no ensino fundamental a temática encontra-se inserida em ciências), tornando-se evidente a preocupação para produção de práticas pedagógicas e pesquisas que discutam a EA nas aulas de química, permitindo, desse modo, uma articulação dos saberes dos professores com os alunos enquanto fortalece o trabalho docente.

No bojo do contexto de ensino superior, as universidades consistem de espaços de transformação da sociedade por meio do desenvolvimento intelectual e da liberdade de pensamento. Segundo Thomas (2013, p. 315) elas buscam "favorecer a situação na qual os sujeitos possam ser protagonistas da transformação da realidade concreta". Neste âmbito, as atividades, práticas, pesquisas e currículo possuem grande destaque e diversos trabalhos têm sido desenvolvidos no sentido de fomentar ações de sustentabilidade para diagnosticar a situação atual do ensino superior, inclusive atuando como ferramentas para a avaliação da EA. Dos trabalhos analisados, 12\% atingem a comunidade externa à universidade e revelam que foram produzidos como resultados de ações desenvolvidas em disciplinas de graduação, excertos de dissertação, projetos de extensão, fornecendo essencialmente a integração da comunidade acadêmica com as pessoas da região onde a universidade está inserida, ou seja, isto faz com que a EA não fique somente nas escolas ao permear todas as esferas sociais e permitir que a discussão transcenda o discurso comum de preservação ambiental e fervilhe numa conscientização cada vez maior.

Os trabalhos essencialmente teóricos representaram 5\% nessa busca. Estes materiais tinham em sua estrutura uma análise crítica e reflexiva sobre a EA. Logo, ao abordarem um contexto reflexivo, se tornam importantes fontes de debates que auxiliam uma busca por uma compreensão sobre as práticas e correntes voltadas à EA. Observou-se a incidência de poucas publicações que traziam reflexões da EA atreladas com os níveis no ensino fundamental II, EJA e técnico. Essa ausência de níveis de ensino mostra que as modalidades da educação básica e profissionalizante, setores expressivos, podem ainda ser 
fortemente exploradas visando estimular práticas que permitam aos estudantes uma tomada de consciência da crise socioambiental e favoreçam uma reflexão de transformação de suas relações com a natureza, sustentabilidade e qualidade de vida.

Segundo Alentin (2014, p.63), "quando associamos a formação continuada de professores com a Educação Ambiental (EA), os problemas se ampliam e revelam-se preocupantes tanto no que se refere aos pressupostos da EA bem como ao tipo de formação que se pretende realizar". Verifica-se esse cuidado com a formação continuada de professores, pois houve um número relevante de publicações neste campo e representam $12 \%$ dos trabalhos. É importante que o professor seja uma fonte de informações sobre questões da EA para seus estudantes, pois ele tem a função de mediador na construção de saberes ambientais, fornecendo ações teóricas e práticas que podem proporcionar um processo contínuo de aprendizagem sobre EA, além de mudanças de posturas em relação ao meio. Neste contexto, o artigo 11 da Política Nacional de Educação Ambiental (PNEA) traz a obrigatoriedade da dimensão ambiental nos currículos de formação de professores. Assim podemos considerar que os trabalhos publicados para formação continuada de professores representam um aspecto importante para a realização de atividades voltadas à EA nas escolas porque servem como um elemento de aproximação entre ela e a realidade escolar. No entanto, Santos et al. (2014) nos alertam que é fundamental que temas ambientais sejam discutidos desde a formação inicial do professor.

\subsection{Temáticas ambientais}

Considerando a importância das temáticas ambientais, é pertinente considerar que as práticas e pesquisas no campo da EA devem oferecer reflexões e, por consequência, propiciar conhecimentos para a compreensão dos fenômenos naturais, das ações humanas e suas consequências ao meio ambiente. Desse modo, com os conteúdos associados às temáticas ambientais que sejam amplamente contextualizados poderão ajudar a compreender a relação integral do mundo em que vivemos, pois, a consciência e as atitudes dos alunos em relação ao meio ambiente podem depender da imersão da EA no ensino em diferentes níveis. O Gráfico 3 mostra as temáticas ambientais categorizadas.

Gráfico 3 - Temáticas Ambientais separadas pelas categorias analisadas.

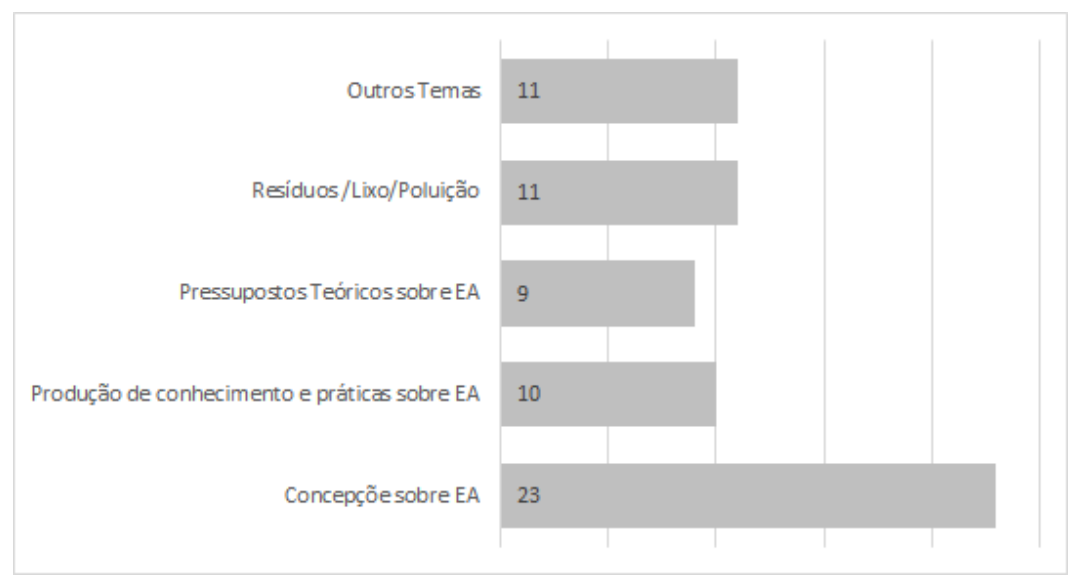

Fonte: Autores.

Nota-se um alto percentual de temas relacionados às concepções sobre EA, representando um total de 23 trabalhos que discutem as percepções de alunos, professores, comunidade, relações e interpretações sobre suas concepções sobre EA. Segundo o dicionário online (DICIO) ${ }^{1}$ “concepções é o plural de concepção, o mesmo que ideias, criações, julgamentos, 
opiniões, pontos de vista". Destarte, a concepção vai além do saber da existência do assunto ao permear as influências e o reconhecimento da Educação Ambiental, pois favorecem espaços para que as pessoas expliquem e exponham as compreensões sobre o meio ambiente ao compreender o ser humano como parte integrante das relações com o meio, contribui para propiciar uma visão mais detalhada e específica de pontos previamente escolhidos.

Os trabalhos com temas relacionados às práticas e produção de conhecimentos sobre Educação Ambiental correspondem a um total de 10. As práticas produzem um processo de reflexão ao oferecer uma oportunidade para criação de posturas dos atores sociais que se mobilizem para a apropriação da natureza ao buscar um processo educativo comprometido com a participação dos educandos sob a lógica que privilegia o diálogo. As divulgações que buscam relações com os pressupostos teóricos corresponderam a 9 trabalhos e pretendem a disseminação dos conhecimentos a respeito do meio ambiente para o desenvolvimento de pensamentos e atitudes com foco em despertar no indivíduo a busca por reflexão e discussões envolvendo a EA. Segundo Tozzoni-Reis (2001, p. 44), a "temática ambiental pode ser uma das sínteses possíveis da crise dos paradigmas da ciência e da organização social, pois os novos e profundos problemas colocados por ela não obtiveram resposta da ciência", assim, mediante definições, concepções, compreensões sobre os pressupostos que aparecem na Educação Ambiental é possível permitir uma profunda reflexão sobre diferentes temas.

O quantitativo de trabalhos com temas como lixo, resíduos e poluição corresponderam a um total de 11 trabalhos. Observa-se, por meio do uso de práticas ambientais menos complexas, que a corrente conservacionista na EA ainda é bastante presente no Brasil (Sorrentino, 1997), pois se organiza em torno da preocupação de preservar os recursos naturais intocados, protegendo a flora e a fauna do contato invasivo e prejudicial e da degradação. Porém, Luzzi (2012) alerta que ao considerar na Educação Ambiental apenas a dimensão ecológica significa reduzir, simplificar e até desconhecer a complexidade das relações presentes entre a educação e o meio ambiente. Em complemento, Leff (2007) diz ser necessário a formação de um saber ambiental e, ainda destaca que ele não deve ser discutido apenas atividades voltadas para a conservação do meio ambiente, pois apesar da abordagem dos problemas ambientais nas práticas pedagógicas, ele sozinho não é suficiente para conscientizar os sujeitos, já que é necessário o entendimento da complexidade da EA para formação crítica e autônoma perante os problemas ambientais. Por isso, esse tipo de prática deve ser fundamentada e utilizada em ações articuladas que contemplem os conteúdos curriculares e sua relação com problemas de ordem social presentes na sociedade contemporânea.

Dando continuidade, outros termos como banana, agrotóxicos, água, softwares educativos e efeito estufa foram encontrados no universo de trabalhos que compuseram a amostra de análise. Certamente, estes temas variados podem trazer uma observação da complexidade e amplitude da EA. Em geral, essas propostas são bastante abrangentes e importantes de serem discutidas porque permite verificar como o saber ambiental pode ser introduzido na busca da compreensão das questões que envolvam o meio ambiente. Assim, os autores buscaram problemas ambientais com forte influência no cotidiano das pessoas para contribuir com a consolidação do conhecimento ao proporcionar práticas que induzam a reflexão quando inseridas no processo educacional por meio de estratégias problematizadoras sobre os fatos relacionados à EA.

\subsection{Características Metodológicas}

Foram categorizadas, também, as características metodológicas utilizadas nos trabalhos com o intuito de traçar um perfil sobre estes aspectos. Para ajudar nessa compreensão, elaborou-se o Gráfico 4, por meio dele é apresentada uma divisão sobre discussões teóricas (Pesquisa) e práticas (Práticas pedagógicas). No total, encontrou-se 42 trabalhos com enfoque mais voltado para aspectos teóricos sobre a EA e 22 trabalhos empíricos sobre Práticas Pedagógicas. 


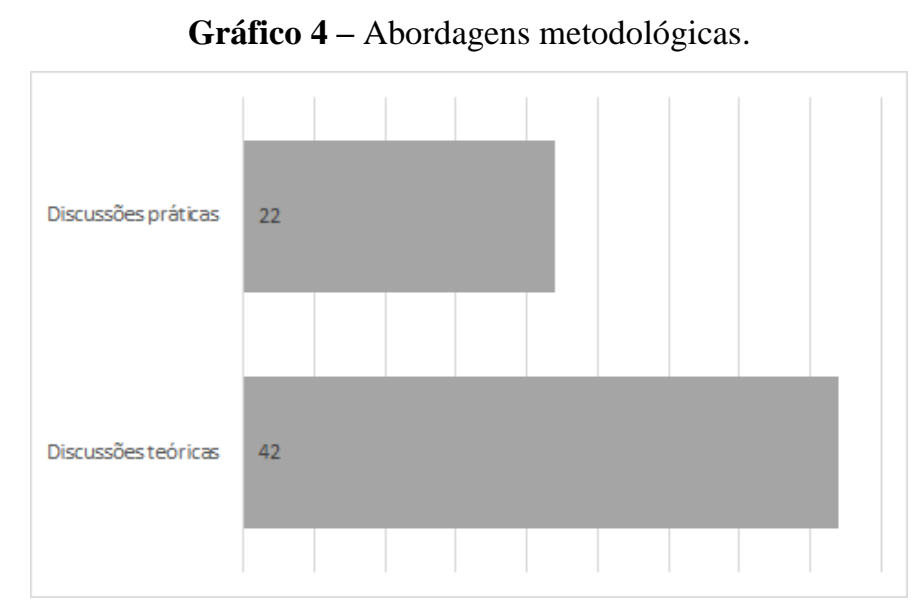

Fonte: Autores.

Segundo Fonseca (2002), a pesquisa possibilita uma aproximação da realidade investigada como um processo constante de compreensão sobre o universo investigado. Com efeito, "a pesquisa científica é o resultado de um inquérito ou exame minucioso, realizado com o objetivo de resolver um problema, recorrendo a procedimentos científicos" (Fonseca, 2002, p. 20). Em complemento, Mendes (2016) defende que a pesquisa científica é uma forma de produzir conhecimento em um determinado processo. Logo, ao realizá-la significa ir além da aparência, permitindo desafios, definição das certezas e incertezas. A pesquisa vivenciada no processo da EA configura um instrumento metodológico que permite observação, reflexão e definição de objetivos no contexto ambiental, explorando os novos conceitos, concepções, e dificuldades vivenciadas na EA.

Nos trabalhos analisados foram encontradas 22 voltados para as Práticas Pedagógicas. Cabe destaca, segundo Machado e Brandão (2017, p. 72), que se trata de um campo de pesquisa que tem uma repercussão bem vista no contexto educacional porque "no ambiente da escola se dão por relações que demonstram a importância do tema ao ser parte do processo formador dos sujeitos, devendo ser gerador de mudanças de comportamento e olhar sobre o meio ambiente". Ainda, corroborando com as ideias dos autores, as atividades vivenciadas com as práticas trazem a EA como um possível caminho para promover a conscientização ambiental, com foco numa mudança de comportamento que consiga permitir condições de mediação sobre questões ambientais e sociais para a construção/reconstrução de conhecimentos. Dando sequência, para uma melhor sistematização dos resultados, a categoria "Características Metodológicas" foi subdividida para melhor discussão e apresentação dos achados da pesquisa, conforme pode-se observar abaixo.

\subsubsection{Métodos de pesquisa, análise e coleta de dados}

Segundo Fonseca (2002), para o desenvolvimento de uma pesquisa científica é indispensável selecionar o método e com base nas características da pesquisa são escolhidas diferentes modalidades para coleta de dados e sua análise. Com base nos trabalhos analisados, nem todos os métodos de pesquisa mostraram o delineamento utilizado. Assim, foi necessária uma classificação baseada nas características encontradas e extrapolações por intermédio dos dados e discussões. Nessa direção, podemos notar no Gráfico 5 uma grande variedade de modalidades de métodos de pesquisa utilizadas em trabalhos sobre a EA. É percebível que a maioria está voltada para a pesquisa documental (13) e a pesquisa do tipo Survey (11). 
Gráfico 5 - Categorização das Modalidades de Pesquisa apresentadas nos trabalhos analisados.

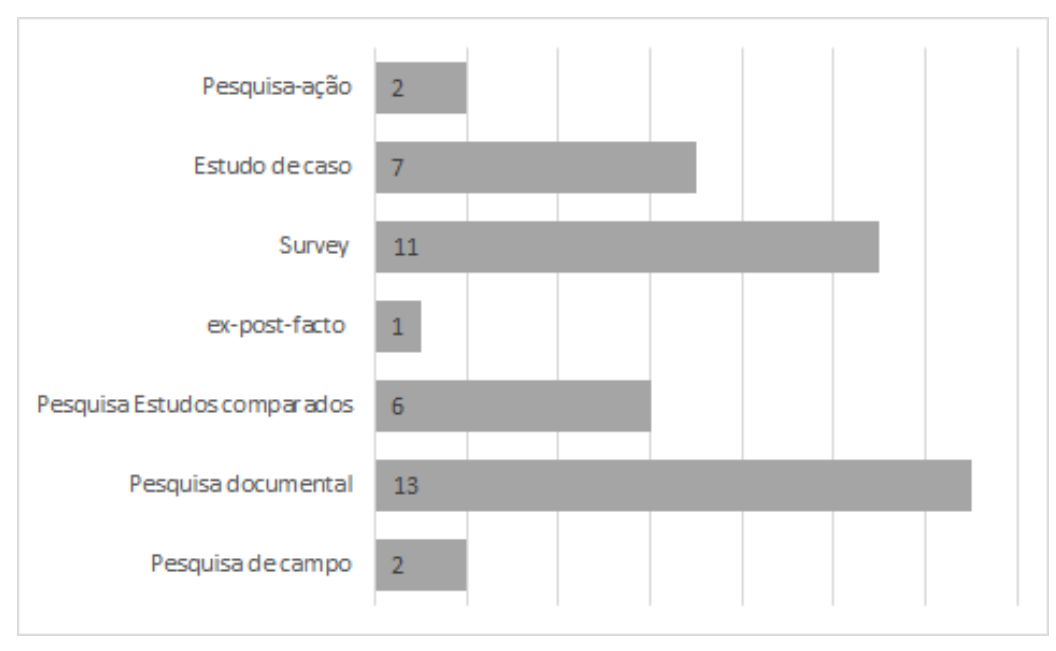

Fonte: Autores.

Acreditamos que os dados demonstram que enquanto uma grande parcela de pesquisadores se interessa em descrever teoricamente como sua pesquisa adotou uma dada abordagem sobre a EA, a outra, no que lhe concerne, se aprofunda no processo de investigação, gerando assim, conscientização amparada pela prática para melhor compreender seu objeto de estudo. Na pesquisa documental, como os dados da EA são obtidos de maneira indireta, isto é, são oriundos de livros, jornais, documentos oficiais, registros estatísticos, filmes, vídeos, entre outros, e possibilitam a quantificação de dados para a realização da pesquisa cujo foco é investigar os conhecimentos e os processos de mudanças sociais e culturais. Cabe mencionar que a modalidade de pesquisa survey pode ser definida como uma “obtenção de dados, informações sobre as características ou as opiniões de um determinado grupo de pessoas, os quais são eleitos como representantes de uma população-alvo e usam um questionário como instrumento de pesquisa" (Fonseca, 2002, p. 33).

No entanto, alguns métodos possuem baixa incidência nas pesquisas sobre EA, tais como, a metodologia de pesquisaação (02), ex-post-facto (01) e pesquisa de campo (02). Já a pesquisa-ação na Educação Ambiental é utilizada como metodologia ativa, pois o investigador abandona o papel único de observador ao assumir uma atitude participativa, trazendo uma série de conhecimentos que serão utilizados para sua análise reflexiva sobre a realidade, e os elementos que a integram.

Por outro lado, a pesquisa ex-post-facto tem por objetivo investigar possíveis relações de causa e efeito entre um determinado fato identificado pelo pesquisador - nesse caso, a Educação Ambiental e o seu estado em períodos anteriores. A principal característica deste tipo de pesquisa está alocada no fato de os dados serem coletados após a ocorrência dos eventos, característica que nos remete a uma reflexão sobre o passado da Educação Ambiental. Já no Estudo de Campo, o investigador perde total controle sobre as variáveis e se limita a observar, identificar e coletar informações sobre o seu objeto de estudo no seu contexto original de vivência (in locus).

Os estudos comparados (06) e estudo de caso (07) consistem de uma parcela representativa dos trabalhos. Segundo a definição de Scarpa e Marandino (1999) podemos notar na primeira modalidade uma busca em comparações de trabalhos que tomam por base dois ou mais estudos sobre a EA e fazem uma análise comparativa entre eles, realizando generalizações e buscando as suas nuances e similaridades. O estudo de caso (07) encontra-se presente nas pesquisas de EA ao enfatizar desse modo o conhecimento do particular. Pode ser caracterizado como um estudo de uma entidade bem definida, ou como um programa, uma instituição, um sistema educativo, uma pessoa, ou uma unidade social. Independe da caracterização, ele procura conhecer em profundidade a causa de uma determinada situação, buscando descobrir o que há nela de mais essencial e 
característico, e passa a ser um fator relevante no aspecto do conhecimento e reflexão da Educação Ambiental porque o pesquisador não pretende intervir sobre o objeto a ser estudado, mas revelá-lo em sua totalidade (Scarpa \& Marandino, 1999).

\subsubsection{Procedimentos de coleta de dados}

Assim, conforme as publicações analisadas, foi possível construir o Gráfico 6 que traz categorizados os procedimentos de coleta de dados mais utilizados quando se desenvolvem pesquisas (conforme o universo de publicações investigadas) sobre a EA, sendo, portanto, documentos (diretrizes do MEC, Projeto Político Pedagógico, Roteiros de aulas experimentais), livros didáticos e periódicos (17).

Gráfico 6 - Instrumentos de coleta de dados dos trabalhos analisados.

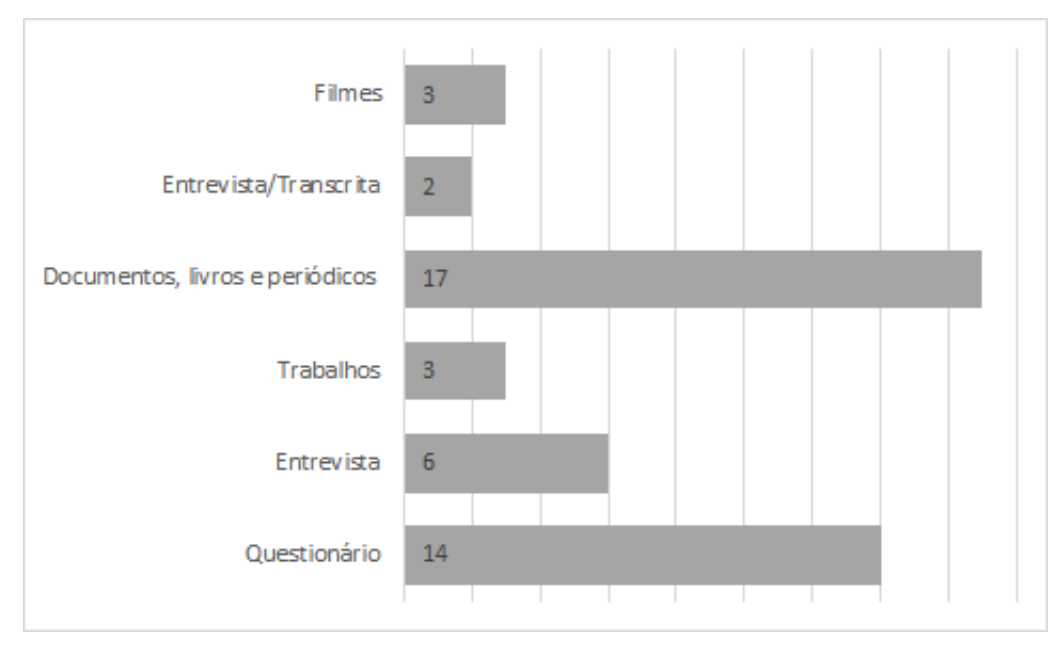

Fonte: Autores.

A maioria dos recursos de pesquisa detectados é de fácil acesso, podendo ser utilizados com maior frequência para se analisar a qualidade e quantidade de diferentes materiais pedagógicos produzidos no âmbito da EA. Isto permite uma visualização global das atividades desenvolvidas sendo úteis para traçar comparativos, levantar possíveis mudanças, entre outros.

Os questionários possuem a segunda maior representação (14). Isso ocorre por ser um instrumento de grande abrangência, fácil, e de rápida aplicação, principalmente no público-alvo pretendido na EA, sendo composta por uma técnica de coleta de dados quando é aplicado criteriosamente, pode apresentar elevada confiabilidade, além de ter um custo razoável. Observamos o uso de outras técnicas como o caso de entrevistas (06) e entrevistas transcritas (02). Algumas publicações buscaram a coleta de dados em trabalhos concluídos de educação ambiental (03). Verificamos trabalhos (03) com análises de filmes, com questões relacionadas à Educação Ambiental, buscando compreensão e aplicação da educação nos meios tecnológicos. Segundo Vigorena e Battisti (2012) existe uma variedade de técnicas de coleta que podem ser combinados (entrevistas, questionários, observações e análises de documentos) para a investigação de um fenômeno. Essa combinação de múltiplas fontes de evidência é um fundamento importante para criação de um banco de dados e representa um processo de múltiplas percepções para esclarecer significados e conhecimentos da EA.

\subsubsection{Práticas pedagógicas}

Para Franco (2016), as práticas pedagógicas incluem bases importantes como o planejamento e a "sistematização da dinâmica dos processos de aprendizagem até a caminhada no meio de processos que ocorrem para além da aprendizagem, de 
forma a garantir o ensino de conteúdos e atividades considerados fundamentais para aquele estágio de formação do aluno" (p. 547). Associada a essa temática, a interdisciplinaridade na Educação Ambiental favorece o desenvolvimento de diferentes possibilidades de trabalhá-la, a transmissão e reconstrução dos conteúdos disciplinares, constituindo conceitos fundamentais para reflexão e superação da fragmentação dos saberes ambientais (Leff, 2011), além disso, "a inserção da interdisciplinaridade, e de suas metodologias, torna-se essencial para se apreender o sentido da complexidade do mundo dos fatos de forma sistêmica" (Nóbrega \& Cleophas, 2016, p. 607).

Os trabalhos que possuem alguma abordagem prática/experimental em EA no ENEQ (Gráfico 7) mostraram uma grande preocupação em exibir detalhamentos dos planos de aulas e propostas de ensino (13), destes, 03 possuíam abordagens interdisciplinares. Estas atividades apresentam informações sobre a necessidade de propostas de práticas educacionais na Educação Ambiental. Certamente, as consequências naturais deste processo resultarão na contribuição para a formação de cidadãos conscientes, capazes de atuar criticamente na sociedade. Elas também têm o interesse de relatar as experiências vivenciadas para que outros docentes possam reaplicar as atividades que demonstram ser exitosas. Segundo Knechtel (2001, p.129) o "enfoque interdisciplinar dentro do contexto educacional, torna-se uma imprescindível contribuição à reflexão e ao encaminhamento de soluções das dificuldades referentes à investigação e ao ensino e para a reconstrução do conhecimento".

O Gráfico 7 apresenta quantitativos relacionados às práticas pedagógicas encontradas nos trabalhos do ENEQ.

Gráfico 7 - Quantitativo das Práticas Pedagógicas.

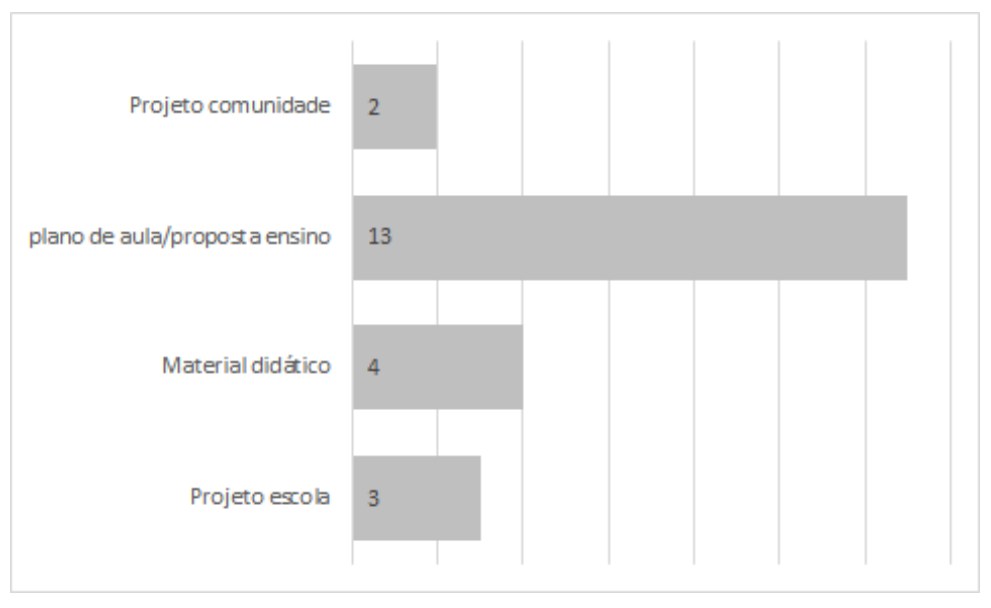

Fonte: Autores.

Das demais categorias, a produção de Materiais Didáticos (Jogos, softwares, apostila de experimentos) foi encontrada em 04 trabalhos. Este quantitativo denota uma lacuna nesse campo de elaboração de recursos para uso em sala de aula. Santos (2014) alega que um material didático (MD) não é só o recurso disponível, mas sim, uma proposta didática do professor, logo, a produção de MD considera um processo de pesquisa no qual o professor elabora ou organiza recursos didáticos tendo como meta atender os objetivos específicos de aprendizagem traçados para uma dada atividade.

Portanto, nos trabalhos analisados foram encontrados projetos educacionais sobre Educação Ambiental, desenvolvidos majoritariamente nas escolas (04) e nas comunidades (02). Esses projetos representam um importante lócus transformador da realidade inerente à Educação ambiental. Nesse viés, Cruz et al. (2017) afirmam que o desenvolvimento de projetos de educação ambiental é uma estratégia para a formação de cidadãos conscientes sobre a importância de preservação do meio ambiente e responsáveis por aprofundar os olhares para questões de sustentabilidade. Além disso, Schröder, Wals e Koppen (2020) consideram que na educação ambiental as escolas devem ser transformadas em locais onde a interação e a aprendizagem conjunta entre ela e os membros da comunidade local podem florescer. 


\subsection{Referenciais Teóricos}

Nesta categoria buscou-se identificar os principais referenciais teóricos relacionados à EA que foram utilizados pelos autores para embasar as suas discussões nos trabalhos completos. O Gráfico 8 apresenta a síntese desta amostragem.

Gráfico 8 - Principais referenciais teóricos citados relacionados à EA, nos trabalhos do ENEQ de 2010 a 2018.

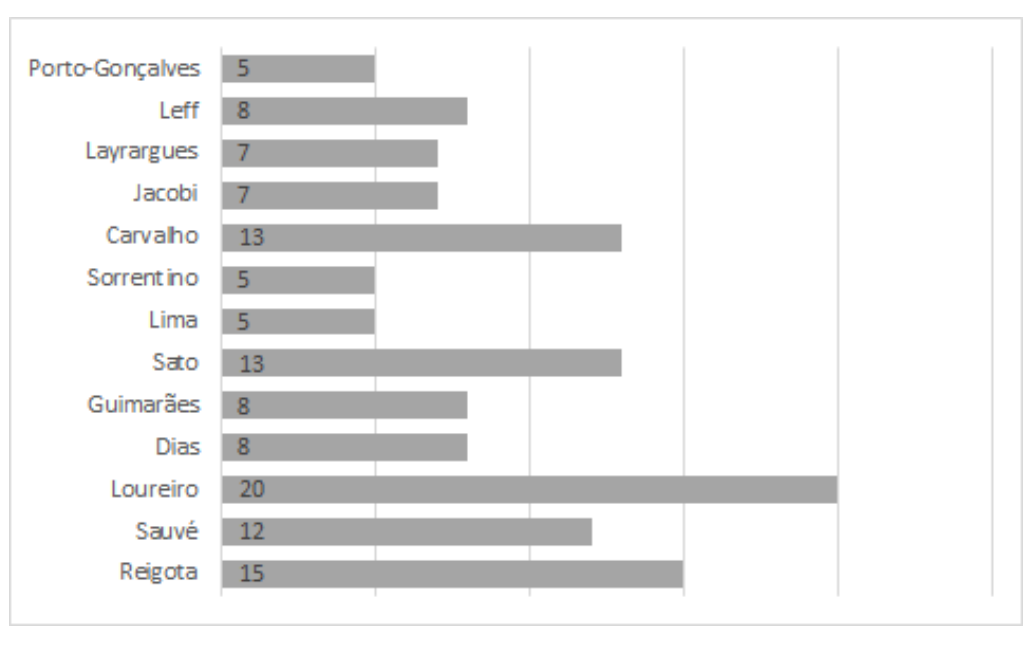

Fonte: Autores.

A organização dos dados coletados mostra no total que 13 autores foram citados no mínimo 5 vezes cada (como critério adotado nesta pesquisa, autores com menos de 5 citações não foram incluídas nesta pesquisa. Para uma análise dos referenciais teóricos destes autores seria necessário um estudo mais detalhado do conjunto de suas publicações, porém, o objetivo aqui é trazer uma contribuição inicial. Por isso, apenas identificamos os referenciais teóricos e realizamos uma breve discussão sobre alguns pontos de interesse.

Os documentos oficiais (Brasil) obtiveram 22 citações nos trabalhos, todavia, não aparecem no Gráfico 8, pois representam um compilado de documentos diretrizes, formado por leis, propostas oficiais de políticas públicas para a educação, Educação Ambiental, além de resoluções oriundas dos órgãos oficiais, no entanto, não possuem autoria de pensamento e construção explícita. Os mais utilizados nos trabalhos levantados são: os Parâmetros Curriculares Nacionais (PCN`s), a Política Nacional de Educação Ambiental (Lei 9.795/99) e o ProNEA (Programa Nacional de Educação Ambiental). As divulgações corroboram com esses documentos, em definições sobre os princípios e fundamentos da Educação Ambiental, traçando diretrizes, conceitos e categorias. Segundo Sorrentino, Trajber e Ferraro Júnior (2005, p. 290), os Ministério da Educação e do Meio Ambiente, como órgãos gestores da política, definem a educação ambiental como "processos por meio dos quais o indivíduo e a coletividade constroem valores sociais, conhecimentos e habilidades, atitudes e competências voltadas para conservação do meio ambiente", e enfatizam a questão da interdisciplinaridade metodológica e epistemológica da EA como "componente essencial" da educação. Vale salientar que a Base Nacional Comum Curricular (BNCC) não foi encontrada devido ao recorte temporal adotado em nossa pesquisa.

Dentre os autores mais citados, Loureiro foi citado em 20 trabalhos (31\%). Tal autor de inúmeros livros e artigos em EA, suas principais obras de citação são: "Trajetórias e fundamentos da educação ambiental (Cortez, 2012)", "A questão ambiental no pensamento crítico: natureza, trabalho e educação (Quartet, 2007)", e "Educação Ambiental: repensando o espaço da cidadania. Cidadania e meio ambiente" (Cortez, 2011). Ademais, o Capítulo de livro mais citado nos trabalhos do ENEQ foi: "Pensamento complexo, dialética e educação ambiental" (Cortez, 2011). As citações trazem os fundamentos do 
autor sobre a necessidade de superação das propostas de EA ingênuas e sem compromisso, tanto as políticas como sociais, buscando sempre atividades consistentes, comprometidas com a construção da sociedade mais justas e igualitárias.

Reigota ocupa o segundo lugar (15 citações) na lista dos autores com maior número de referências em trabalhos de educação ambiental do ENEQ. Seus livros mais utilizados nos trabalhos analisados são: "O que é educação ambiental" (Brasiliense, 1994), "A floresta e a escola: por uma educação ambiental pós-moderna" (Cortez, 1999), "Meio ambiente e representação social" (Cortez, 1994), "Ecologistas" (Edunisc, 1999), "Ecologia", "elites e intelligentsia na América Latina: Um estudo de suas representações sociais" (Annablume, 1999). Os autores dos trabalhos concordam com Reigota sobre os ideais do desenvolvimento de uma EA com caráter crítico que busque a formação dos sujeitos críticos-reflexivos e transformadores, que precisam alcançar uma visão de educação que compreenda a problematização, contextualização e interdisciplinaridade. As autoras Sato (13) e Carvalho (13) também possuem um número expressivo de citações, cujas obras mais citadas das referidas autoras foram: "Educação Ambiental" (2004) e "Educação Ambiental: a formação do sujeito ecológico" (2004), respectivamente.

Lucie Sauvé aparece em 12 citações com foco principalmente com seu livro "Educação ambiental e desenvolvimento sustentável: uma análise complexa" (1997). Os estudos de Guimarães são encontrados em 08 citações e trazem a reflexão da interdisciplinaridade, complexidade, práxis para superação da fragmentação e fragilização das práticas educacionais da EA. Em relação à complexidade da formação de um "saber ambiental", Enrique Leff é referenciado em 08 trabalhos e engloba temas como sustentabilidade, interdisciplinaridade, cultura e sociologia. Layrargues é citado em 07 trabalhos e discute a EA e apresenta argumentos que justificam a importância da sociologia ambiental, já Sorrentino foi citado em 05 trabalhos e tem suas pesquisas voltadas ao planejamento, participação e formação cidadã.

Verificamos que nos trabalhos analisados há um embasamento teórico em caráter humanista, holístico, interdisciplinar e participativo na Educação Ambiental, que busca o compromisso em contribuir com a renovação do processo educativo, pois trazem avaliações críticas, conteúdos adequados à realidade local, e apresenta aos educandos algumas ações concretas de transformação da realidade. As reflexões e contribuições em relação à EA interpretam o ambiente e captam as dinâmicas de interação culturais, sociais e naturais em determinadas relações socioambientais. De modo que apresentam preocupações inerentes ao contexto ambiental e buscam apresentar as concepções da EA como transmissora de conhecimentos para a transformação do mundo.

\section{Considerações Finais}

A realização deste levantamento realizado por meio de uma Revisão Sistemática da Literatura teve como foco servir como base para pesquisas futuras. Como resultado, constatou-se um crescimento na produção de trabalhos relacionados a EA ao longo dos anos, impulsionados pela exponencialidade nas formas e meios de divulgação. A existência de diversas abordagens, metodologias e referenciais de EA estão sendo abordadas em diferentes níveis e segmentos da educação básica, Ensino Superior e comunidades, embora a aplicabilidade não seja direta ou evidente num primeiro momento.

Estabeleceu-se a expectativa de que a Educação Ambiental estivesse presente de forma ampla nos níveis de ensino, mas foram encontradas poucas reflexões da EA atreladas com os níveis no ensino fundamental II, Educação de Jovens e Adultos (EJA) e ensino técnico. As temáticas ambientais encontradas são variadas e agregam concepções sobre EA de forma evidente, isto favorece espaços para explicações, exposições, análises e reflexões sobre o tema. Certamente, a grande variabilidade de questões pode trazer em entendimento da complexidade e amplitude da EA contempladas com propostas abrangentes e utilizadas na busca da compreensão das questões que envolvam o meio ambiente.

No total, encontrou-se 42 trabalhos com enfoque voltado para aspectos teóricos sobre a EA e 22 trabalhos sobre Práticas Pedagógicas que contemplam atributos aplicacionais. As características metodológicas dos trabalhos teóricos estão 
relacionadas às pesquisas abordando a EA e tem como intuito explorar as discussões e reflexões. Já os trabalhos envolvendo as práticas pedagógicas utilizaram diversas estratégias e recursos didáticos, mas, de forma geral, os trabalhos práticos em EA mostraram uma grande preocupação em expor planos de aulas e propostas de ensino, dos quais poucos possuíam abordagens interdisciplinares. A produção de Materiais Didáticos incluiu a produção de recursos midiáticos e lúdicos, mostrando uma grande lacuna nesse campo para elaboração de meios que podem ser explorados. Alguns projetos educativos sobre EA foram desenvolvidos na escola e nas comunidades, porém é importante destacar que essas atividades precisam ter continuidade e não ser aplicadas ou conhecidas apenas de modo pontual. Identificou-se os principais referenciais teóricos utilizados, com a finalidade de contribuir para o debate sobre a tendência de consolidação da EA.

A partir do que foi analisado ao longo dos dez anos de publicações do ENEQs, fica evidente a necessidade de se propagar a divulgação e desenvolver novas pesquisas e práticas de EA, buscando diversificar suas atuações nos diferentes níveis de ensino. As reflexões sobre a evolução das teorias, metodologias, referenciais teóricos e abordagens trilhadas pela Educação Ambiental podem promover novas perspectivas e possibilidades nessa área. No geral, os dados e temas que surgem desta revisão demonstram encorajar a intencionalidade, criatividade e inclusão ao desenvolver e ações que visem a qualidade ambiental e práticas de conservação. No entanto, ainda há dificuldades em promover a construção de ambientes educacionais que enfoquem atividades de intervenção em atitudes ambientais positivas.

O presente artigo encontra algumas limitações, como a necessidade de avançar no estudo investigativo sobre a EA, no sentido de ampliar os atores e concepções sociais e políticas ambientais, e analisar a evolução dos referenciais teóricos com um estudo mais detalhado do conjunto das suas publicações, permitindo um maior aprofundamento sobre as questões aqui levantadas, pois, esta diversidade de perspectivas e quadros teóricos revelariam o que os pesquisadores concebem como práticas eficazes no campo da EA no ensino de Química.

Por fim, acredita-se que o presente estudo pode servir como fonte de informação, promovendo maior compreensão de como a EA está sendo difundida no Ensino de Química e, a partir disso, consiga orientar posteriores pesquisas a atuarem em campos específicos, pois pode servir como uma base para o desenvolvimento do conhecimento e tem a capacidade de engendrar novas ideias e direções para a EA.

\section{Referências}

Alentin, L. (2014). A dimensão política na formação continuada de professores em educação ambiental. REMEA - Revista Eletrônica do Mestrado em Educação Ambiental, 31(2), 58-72.

Bardin, L. (1977). Análise de conteúdo. Edições 70.

Bowers, A. W., \& Creamer, E. G. (2021). A grounded theory systematic review of environmental education for secondary students in the United States. International Research in Geographical and Environmental Education, 30(3), 184-20.

Brasil MEC. (2012). CNE/CResolução 2, de 15 de junho de 2012. Estabelece as Diretrizes Curriculares Nacionais para a Educação Ambiental.

Cleophas, M.G., \& Francisco, W. (2018). Metacognição e o ensino e aprendizagem das ciências: uma revisão sistemática da literatura (RSL). Amazônia: Revista de Educação em Ciências e Matemáticas, 14(29), 10-26.

Cruz, J., Rieger, A., \& Bernad, T. (2017). A importância da continuidade de projetos de educação ambiental, realizados em escolas para a formação de cidadãos. Anais do Salão de Ensino $e$ de Extensão, Universidade de Santa cruz do sul. <https://online.unisc.br/acadnet/anais/index.php/salao_ensino_extensao/article/view/17042/0>

Dicio. (2020). Dicionário Online de Português. 7Graus.

Donato, H., \& Donato, M. (2019). Stages for Undertaking a Systematic Review. Acta Médica Portuguesa, 32(3), $227-235$.

Emery, F. S.; Santos, G. B.; \& Bianchi, R. C. (2010). A química na natureza. São Paulo: Sociedade Brasileira de Química. ENEQ’s Anteriores. Encontro nacional do ensino de química-ENEQ, 2018.

Franco, M. A. R. S. O. Prática pedagógica e docência: um olhar a partir da epistemologia do conceito. Rev. Bras. Estud. Pedagog., 97(247), 534-551, 2016. INEP (2004). Instituto Nacional de Estudos e Pesquisas Educacionais. Anísio Teixeira. Ministério da Educação. < http://portal.inep.gov.br/artigo//asset_publisher/B4AQV9zFY7Bv/content/aumenta-numero-de-escolas-com-educacao-ambiental/21206> 
Kato, D. S., \& Kawasaki, C. S. (2011). As concepções de contextualização do ensino em documentos curriculares oficiais e de professores de ciências. Ciênc. educ., 17(1), 35-50.

Knechtel, M. R. (2001). Educação Ambiental: uma prática interdisciplinar. Desenvolvimento e Meio Ambiente, 3, 125-139.

Layrargues, (coord.) (2004). Identidades da educação ambiental brasileira, Ministério do Meio Ambiente. Diretoria de Educação Ambiental. Brasília: Ministério do Meio Ambiente, $156 \mathrm{p}$.

Leff, E. (2011). Complexidade, interdisciplinaridade e saber ambiental. Olhar de Professor, 14(2), 309-335.

Leff, E. (2007). Epistemologia Ambiental. (4a ed.), Cortez.

Vigorena, D. A. L., \& Battisti, S. S. (2012). Procedimentos de coleta de dados em trabalhos de conclusão do curso de Secretariado Executivo da Unioeste/PR. Secretariado Executivo em Revista, 7(2), 1-15.

Luzzi, D. (2012). Educação e meio ambiente: uma relação intrínseca. Manole.

Machado, G. I., \& Brandão, J. B. (2017). Parcerias institucionais para promoção da prática cotidiana da Educação Ambiental em escolas. REMEA - Revista Eletrônica do Mestrado em Educação Ambiental, 34(1), 72-91.

Marques, R., Raimundo, J. A., \& Xavier, C. R. (2019). Filosofia na/da Educação Ambiental: a complexidade das produções do primeiro quindênio do século XXI. REMEA - Revista Eletrônica do Mestrado em Educação Ambiental, 36(3), 24-42.

Mazzarino, J. M., \& Rosa, D. C. (2013). Práticas Pedagógicas em Educação Ambiental: o necessário caminho da auto-formação. Ambiente \& Educação, 18(2), p.121-144.

Megid-Neto, J. (1999). Tendências da pesquisa acadêmica sobre o ensino de ciências no nível fundamental. (Doutorado em Educação). Universidade Estadual de Campinas, São Paulo.

Mendes Filho, A. (2016). Utilizando o Scratch para valorizar a autoria e autonomia discente em projetos pedagógicos interdisciplinares nos conteúdos dos parâmetros curriculares nacionais (PCNs). (Dissertação de Mestrado). Universidade Estadual de Campinas. Faculdade de Educação, Campinas.

Nóbrega, M. L. S., \& Cleophas, M. G. (2016). A educação Ambiental como proposta de formação de professores reflexivos: das práticas contextualizadas à ambientalização no ensino de ciências. Inter-Ação, 41(3), 605-628.

Santos, J. G., \& Rodrigues, C. (2018). Educação ambiental no ensino de Química: a “água” como tema gerador. REMEA - Revista Eletrônica do Mestrado em Educação Ambiental, 35(2), 62-86.

Santos, M. C. (2014). A importância da produção de material didático na prática docente. VII Congresso brasileiro de Geógrafos, Vitória -ES. <http://www.cbg2014.agb.org.br/resources/anais/1/1404098564_ARQUIVO_AImportanciadaProducaodeMaterialDidaticonaPraticaDocente.pdf>

Schröder, L-M. U., Wals, A. E. J., \& Koppen, C. S. A. (2000). Analysing the state of student participation in two Eco-Schools using Engeström's Second Generation Activity Systems Model. Environmental Education Research, 26(88), 1088-1111.

Silva, E. L., \& Marcondes, M. E. R. (2010). Visões De Contextualização De Professores De Química Na Elaboração De Seus Próprios Materiais Didáticos. Ens. Pesqui. Educ. Ciênc., 12(1), 101-118.

Sorrentino, M. (1997). "Vinte anos de Tbilisi, cinco da Rio 92: A Educação Ambiental no Brasil". Debates Socioambientais. CEDEC, ano II, nº 7, 3-5.

Sorrentino, M., Trajber, R., \& Ferraro Júnior, L. A. (2005). Educação ambiental como política pública. Educ. Pesqui., 31(2), 285-299.

Tanaka, H. (2000). Environmental chemistry education for the 21st Century. Journal of the Indian Chemical Society, 77(11), 531-538.

Thomaz, C. E., \& Camargo, D. M. (2007). Educação Ambiental no Ensino Superior: Múltiplos Olhares. REMEA - Revista Eletrônica do Mestrado em Educação Ambiental, 18, 303-318.

Tozzoni-Reis, M. F. C. (2001). Educação Ambiental: referências teóricas no ensino superior. Interface, 5(9), 33-50.

Tozzoni-Reis, M. F. C. (2009). Metodologia da Pesquisa. (2a ed.), IESDE Brasil S.A. 136 p. 